\title{
The effect of predictive cues on freezing in rats
}

\author{
ROBERT C. BOLLES and ALEXIS C. COLLIER \\ University of Washington, Seattle, Washington 98195
}

\begin{abstract}
Rats were given five shocks over a 5 -min period and then observed for $20 \mathrm{~min}$. Much more freezing was observed in animals that remained in the shock situation than in animals moved to another situation. Freezing, therefore, seems to be controlled primarily by external shock-related cues. Freezing appears to be also partly controlled by the inherent stimulus properties of the situation.
\end{abstract}

It has been known for some time that rats tend to become immobile, that is, freeze, in situations where they receive electric shock. Freezing is usually unwanted behavior, behavior that must be gotten rid of if the rat is to perform properly on, say, an avoidance-learning task. But there is now a growing interest in freezing both for its own sake because it is such a prominent part of the frightened rat's behavior repertory, and because a better understanding of freezing may lead to a better understanding of defensive behavior in general. Thus, Blanchard and Blanchard (1969) proposed that an immobile posture, which they designated "crouching," could be used as an index of fear. Anisman and Waller (1971) explained different effects in active and passive avoidance in terms of immobility responses, such as freezing, acquired during prior shock exposure and they were able to manipulate such responses experimentally. Bolles and Riley (1973) found that freezing was very rapidly acquired as an avoidance response.

Bolles and Riley (1973) reported that when rats were shocked every $15 \mathrm{~min}$, they froze during $77 \%$ of the intershock interval. Blanchard, Dielman, and Blanchard (1968) found some elevation in the level of crouching hours after the administration of a single shock. How are we to explain this great persistence of immobility following aversive stimulation? Is it due to reverbration of some sort in the autonomic nervous system? Is it due to arousal of the pituitary-adrenal system? The present study supports the Blanchards' conclusion that the persistence of freezing, and crouching, is not primarily due to any such endogenous factor, but is, rather, due to the continued presence of external cues that predict shock. Our evidence for the external control of immobility is, like theirs, the relatively low incidence of freezing in rats that are shocked in one situation and tested in another.

\section{METHOD}

\section{Subjects}

The subjects were 40 naive Wistar rats, approximately 120 days of age.

Supported by Research Grant GB-40314 from the National Science Foundation. Requests for reprints should be addressed to the first author, Department of Psychology, University of Washington, Seattle, Washington 98195.

\section{Apparatus}

Two boxes were used for conditioning and testing. One, designated the "long" box, was $76 \mathrm{~cm}$ long, $20 \mathrm{~cm}$ wide, and 18 $\mathrm{cm}$ high. It was placed in a sound-attenuating chamber and lighted by a $15-\mathrm{W}$ bulb. The floor of the box was constructed of $1-\mathrm{cm}$ stainless steel bars spaced $2.5 \mathrm{~cm}$ center to center; the sides were also stainless steel. Background noise of approximately $76 \mathrm{~dB}$ was provided by a ventilation fan.

The second box was designated the "square" box. It was 29 by $35 \mathrm{~cm}$, and $31 \mathrm{~cm}$ high. Illumination was once again provided by a $15-\mathrm{W}$ bulb in the ceiling. Background noise of approximately $82 \mathrm{~dB}$ was provided by a white noise generator. The floor of the box was constructed of $1-\mathrm{cm}$ stainless steel bars spaced $2 \mathrm{~cm}$ center to center. The sides of the chamber were painted flat black. Thus, the two boxes were discriminably in several respects. The experimenter sat in the dark to observe the animals without being seen by them. A GrasonStadler shock generator provided scrambled shock of nominal $1.0 \mathrm{~mA}$ intensity to each box.

\section{Procedure}

The basic design was a 2 by 2 factorial in which rats were shocked in either the long box $(\mathrm{L})$ or the square box $(\mathrm{S})$ and then observed in either the same box or the other one. Eight animals were assigned randomly to each experimental condition. These groups may be designated L-L, L-S, S-L, and S-S, where the first letter indicates where shock was presented and the second indicates where the animal was observed. An experimental subject was first placed in the appropriate box and allowed a 1 -min habituation period. Then a 0.5 -sec shock was presented. Altogether, five shocks were presented at 1-min intervals. One min after the fifth shock the subject was picked up and either returned to where it had been shocked or placed in the other box, depending upon which group it was in.

Observation of the animal began $1 \mathrm{~min}$ later and continued for $20 \mathrm{~min}$. There was no shock during this period. The occurrence of all freezing was recorded. Freezing was defined by the absence of body movement together with the absence of the whisker and nose movements characteristic of sniffing. Freezing was observed while animals were in a variety of postures, but it occurred most often in a characteristic sitting posture. It seemed to be accompanied by a tenseness or rigidity of the body. In addition to obtaining continuous records of freezing behavior, a time-sampling technique was used to assess the incidence of grooming, activity (body movement and/or exploration), and inactivity other than freezing (sitting or lying). An unshocked control group was constituted of two animals placed in each of the four combinations of $L$ and $S$. The control animals were placed in one box for six min, then picked up and either placed in the same box or the other one, and then observed for $20 \mathrm{~min}$. All animals were run at approximately the same time of day.

\section{RESULTS}

Freezing was virtually nonexistent among the control animals (averaging only $0.22 \%$ of all behavior), which is 


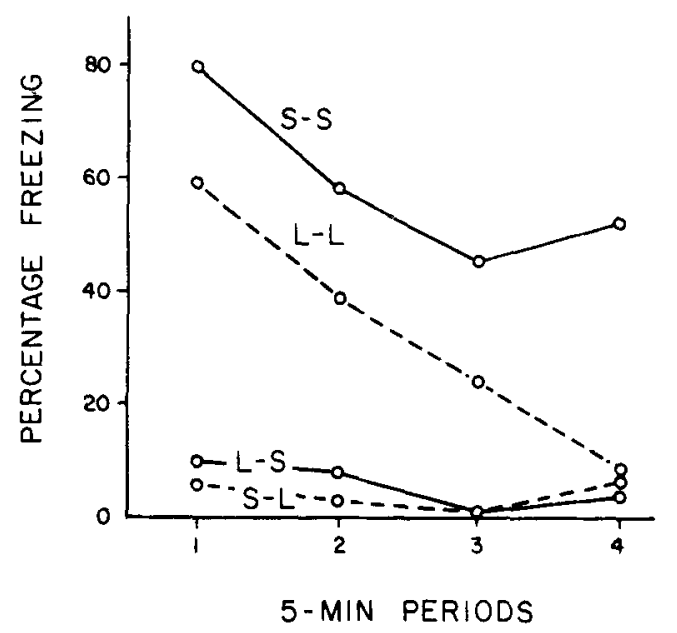

Figure 1. The mean incidence of freezing during a 20 -min test in a long box (L) or a square box (S) after being shocked in either $L$ or $S$. The first letter in the legend indicates where the rats were shocked; the second, where they were tested.

why only one pooled control group was used. The mean proportion of time each experimental group spent freezing during successive 5 -min periods of observation is shown in Figure 1.

An analysis of variance of total freezing times revealed a highly significant effect attributable to same (L-L and S-S) vs. different (L-S and S-L) $[\mathrm{F}(1 / 28)=35.5$, $\mathrm{p}<.001]$. There was also a significant effect of observation situation $[F(1 / 28)=4.48, p<.05]$. The interaction (i.e., whether shock was received in $\mathrm{S}$ or $\mathrm{L}$ ) was not significant, $F=3.30$. All experimental groups showed significantly more freezing than the control group: the smallest $\mathrm{t}=2.74, \mathrm{p}<.05$. It should be noted that freezing scores were highly skewed under all conditions. A few animals in the high-freezing groups froze relatively little, and a few in the low-freezing group showed appreciable freezing. Describing the behavior in terms of means, therefore, tends to reduce the differences between groups. Median freezing scores during the first $5 \mathrm{~min}$, which may be more representative, were $80 \%$ for animals observed in the shock box and $2 \%$ for animals observed in the other box.

The results of time sampling other behaviors during the observation period are summarized in Figure 2. These data are consistent with the previous analysis as far as freezing is concerned: same vs. different is the major factor controlling the incidence of freezing, and there is some asymmetry in that more freezing occurred in $\mathrm{S}$ than in $\mathrm{L}$. But these data also indicate what the rats were doing when they were not freezing: predominantly being active in $\mathrm{L}$ and being inactive in $\mathrm{S}$. The percentage of all nonfreezing that was classified as activity was $63 \%$ in $L$ as against $44 \%$ in $S$. This difference was significant: $\mathrm{p}<.05$.

\section{DISCUSSION}

The major finding here is that rats froze about 20 times as much during a 20 -min period in the situation where thay received shock than in another situation where shock had never been experienced. Thus, it appears that the principal factor in freezing is the presence of cues that have recently been correlated with shock. Blanchard and Blanchard (1969) came to the same conclusion with regard to what they called "crouching"; the incidence of crouching following shock depended primarily upon the presence of shock-related cues.

It is interesting that crouching and freezing, which are defined quite differently, should show a similar functional dependence upon shock cues, and should be comparable indices of fear in the rat. Crouching is a posture, essentially what we call sitting (R. J. Blanchard, personal communication), whereas freezing is a more specific coordination of behaviors, which is characterized by absence of sniffing, body tenseness, shallow breathing, etc. Thus, the Blanchards' crouching includes much of our freezing and most of our inactivity (since there is little lying down in $20 \mathrm{~min}$ ). So it is not surprising that crouching seems to occur at a higher level and to persist longer than freezing. In either case, however, i.e., regardless of which behavior is indexed, the persistent behavioral effects of shock seem to depend primarily upon external predictors of shock.

This is not to say that there are no persistent internal effects of shock. There obviously are such effects; the activity of the pituitary-adrenal system, once aroused, declines gradually for many minutes. Thus, for example, Coover, Ursin, and Levine (1974) found heightened levels of plasma corticosterone $20 \mathrm{~min}$ after traumatic stimulation and $10 \mathrm{~min}$ after rats are removed from an aversive situation. Brush and Levine (1966) reported that the level of plasma corticosterone had not returned to normal $60 \mathrm{~min}$ after their rats were shocked. It is interesting to note, however, that this prolonged elevation was only found when the rats remained in the shock situation. Rats that were removed to their home cages for $60 \mathrm{~min}$ showed normal corticosteroid levels.

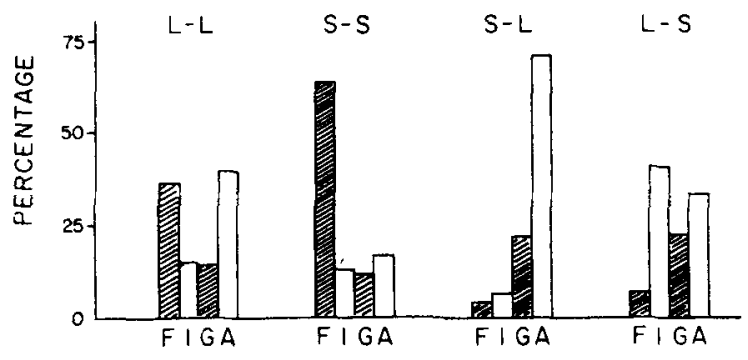

Figure 2. The mean incidence of freezing, inactivity, grooming, and activity for the four groups. 
Brush and Levine's results, therefore, provide support for the proposition that the rat's emotional state (fear) is primarily controlled by external cues rather than by endogenous factors. Their results also suggest that the physiological state of arousal (e.g., corticosterone level) is itself at least partly controlled by more psychological factors such as the rat's expectancy of shock (see also Coover et al., 1974).

The present results indicate that in addition to being controlled by the expectancy of shock, freezing is also partly controlled by the inherent stimulus properties of the test situation. The incidence of freezing, and of different nonfreezing behaviors, depended upon whether the animals were put into the square box or the long box. Although the test boxes differed on a variety of stimulus dimensions, we may suppose a relevant dimension was simply the different geometries of the two boxes. A good deal more running back and forth was observed in $\mathrm{L}$ than in $\mathrm{S}$. It is as if the geometry of $\mathrm{L}$ "invites" running in the rat, and this behavior then competes with and reduces the amount of freezing that would otherwise occur when the rat is frightened.

\section{REFERENCES}

Anisman, H., \& Waller, G. Effects of methamphetamine and shock duration during inescapable shock exposure on subsequent active and passive avoidance. Journal of Comparative and Physiological Psychology, 1971, 77, 143-151.

Blanchard, R. J., \& Blanchard, D. C. Crouching as an index of fear. Journal of Comparative and Physiological Psychology. $1969,67,370-375$.

Blanchard, R. J., Dielman, T. E., \& Blanchard, D. C. Prolonged aftereffects of a single footshock. Psychonomic Science $1968,10,327-328$

Bolles, R. C.. \& Riley, A. L. Freezing as an avoidance response: Another look at the operant-respondent distinction. Learning and Motivation, 1973, 4, 268-275.

Brush, F. R., \& Levine, S. Adrenocortical activity and avoidance learning as a function of time after fear conditioning. Physiology and Behavior, 1966, 1, 309-311.

Coover, G., Ursin, H., \& Levine, S. Cortic osterone levels during avoidance learning in rats with cingulate lesions suggest an instrumental reinforcement deficit. Journal of Comparative and Physiological Psychology, 1974, 87, 970-977.

(Received for publication February 24, 1975. Revision received June 12,1975 .)

\section{ACKNOWLEDGEMENTS}

We regret that the following consultants were missed in our listing in the November issue. Their help during the past year is gratefully acknowledged.

C. B. Biederman, University of Toronto

P. M. Bronstein, Brooklyn College

Robert A. Butler, University of Chicago

Russell Church, Brown University

Robert L. Collins, Florida State University

Karen Galbraith, Lakeshore Psychiatric Hospital

Peter F. Galvani, SUNY, Brockport

Henry Gleitman, University of Pennsylvania

C. Donald Heth, University of California, Riverside

Jerry Hirsh, University of Illinois

J. A. Hogan, University of Toronto

Ronald R. Hutchinson, Foundation for Behavioral

Research, Augusta, Michigan

Marvin Levine, SUNY, Stony Brook

H. Wayne Ludvigson, Texas Christian University

Kenneth B. Melvin, University of Alabama

Donald Meltzer, Southern Illinois University

J. R. Millenson, McGill University

G. Mitchell, University of California, Davis

Howard Moltz, University of Chicago

J. W. Moore, University of Massachusetts
John R. Platt, McMaster University

Robert A. Rescorla, Yale University

James H. Reynierse, Hope College

David C. Riccio, Kent State University

Dane Russo, University of South Carolina, Spartanburg

N. Schneiderman, University of Miami

James C. Smith, Florida State University

D. D. Thiessen, University of Texas at Austin

C. Tolman, University of Victoria

Paul Touchette, E. K. Shriver Center

Robert L. Welker, University of Pennsylvania

Richard E. Wimer, City of Hope National Medicine

Center

The following are corrections in names and affilia. tions of consultants listed in the November issue:

Robert Griffin, Mercer University

Friedrich K. Stephan, Florida State University

E. Zamble, Queens University 